IN NATURE (vol. xxix. p. 596) there is a letter signed James Graves, in which he says, " as to the magpie or any other bird being able to fix dates exactly to the day, it is unproved and incredible." I do not know what may be the case in regard to birds-nestbuilding, but I can give two instances of the regularity with which birds arrive at certain localities en route northward, whatever may be the state of the weather. During a ten years' residence on the shores of Hudson's Bay, the first Canada goose of the spring migration was seen and generally shot on April 23 . At Toronto on Lake Ontario, large flocks of a pretty little plover called the " black-heart," from a black patch on its breast, pass along the islands, flying northward, on St. George's Day (April 23), and are seldom or never seen even a day before or a day after that date. The poor little birds have a sad time of it for six or eight hours, as a number of sportsmen go out for the occasion and knock them down by the half-dozen or more at every shot. In this case, as in the other, wind and weather appear to cause no difference

4, Addison Gardens, A pril 25

THE ABSORPTION OF WATER BY PLANTS

$A \mathrm{~N}$ ingenious instrument has lately been described by A Dr. J. W. Moll (Archives Neerlandaises, i. xviii.) under the name of the Potometer. It is a modification of Sachs' apparatus for determining the amount of water which a cut branch absorbs in a given time. I have been for some years in the habit of using a form of Sachs' instrument, differing in principle from Moll's apparatus, but resembling it in being especially adapted for making observations at short intervals of time. As the subject of transmission of water through wood is now attracting attention among physiologists, it seems worth while to describe my instrument.

A short piece of thick indiarubber tube is slipped over the cut end of a branch and firmly attached to it by wire ties; the other end of the rubber tube being securely fitted to a glass tube which is filled with water. The other end of the glass tube is closed by an indiarubber cork through which passes a coarse thermometer tube. The apparatus is now fixed so that the free end of the thermometer tube dips into water. As the leaves evaporate the water in the glass tube is sucked up by the cut end of the branch, the loss being constantly made up by a current flowing in through the thermometer tube. If then we can estimate the rate of this current we shall know the rate of absorption of water. This is very simply done by allowing, for a few seconds, the thermometer tube to suck in air instead of water; when a column of air a few millimetres in length has been drawn in, the end of the tube is again immersed in water, and the bubble travels rapidly along the thermometer tube, when its speed is measured by means of a chronograph.

This method appears no doubt to be a rough one, and is open to objections; but 1 believe that it does not give rise to serious errors, and it certainly demonstrates extremely well small changes in the rate of absorption by a cut end of the branch. By means of my instrument observations can be made at very short intervals; for instance, four readings were taken in $\mathrm{I}^{\prime} 5 \mathrm{O}^{\prime \prime}$; it is therefore well adapted for observing rapid changes in the rate of absorption.

I reserve a full discussion of the merits and demerits of the instrument for a later publication.

Experiments, April $1884 .-$ When a branch is first fitted to the instrument the rate of absorption is extremely rapid, owing to causes which need not here be considered, but after a time the rate of absorption (which diminishes with great rapidity) becomes constant. A branch of Portugal laurel (Cerasus lusitnnica) was cut at 930 a.m.,. and was not fitted to the apparatus until 10.15 a.m.

The following table shows clearly the rapid decrease in the rate of absorption : -1

I In this and the following tables I have not given the actual quantities of water absorbed, merely the relative rates of absorption.

$$
\begin{aligned}
& \text { Times h. m. Rate of Absorption }
\end{aligned}
$$

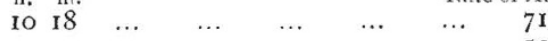

$$
\begin{aligned}
& \begin{array}{lllllll}
20 & \cdots & \cdots & \cdots & \cdots & \cdots & 53 \\
25 & \cdots & \cdots & \cdots & \cdots & \cdots & 40
\end{array} \\
& \begin{array}{llllllll}
\text { II } & 14 & \ldots & \ldots & \ldots & \ldots & \ldots & 26
\end{array} \\
& \begin{array}{lllllll}
35 & \cdots & \cdots & \cdots & \cdots & \cdots & 25 \\
52 & \cdots & \cdots & \cdots & \cdots & \cdots & 25
\end{array}
\end{aligned}
$$

Sachs has called attention to the diminution in the absorption which occurs when cut branches are placed in water, and has shown that the absorbing power can be renovated by cutting a fresh surface at the base of the branch. This effect is well shown with my instrument. ${ }^{x}$

The above-mentioned branch of Portugal laurel which had been placed in water at 9.30 a.m. gave a relative rate of absorption of twenty-four at 12.28 ; at 12.30 , between 6 and $7 \mathrm{~cm}$. were cut off, and the branch was again fitted to the machine, the operation lasting one and a half minutes.

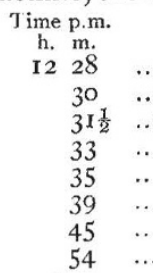

$$
\begin{array}{ll}
\multicolumn{2}{c}{\begin{array}{c}
\text { Rate of } \\
\text { Absirption }
\end{array}} \\
\ldots & 24 \\
\text { fresh } & \text { surface cut } \\
\text { branch replaced } \\
\ldots & 35 \\
\ldots & 30 \\
\ldots & 28 \\
\ldots & 26 \\
\ldots & 26
\end{array}
$$

When the rate of absorption has become constant, any variation in dampness or dryness of the air causes variations in the transpiration of the leaves, and therefore in the rate of absorption. These changes are well shown by my instrument. The following experiment, made with a branch of Portugal laurel shows the amount and rapidity of the increase in absorption caused by exposing the leaves to the sun shining through window-glass:Time a.m. h. $m$.

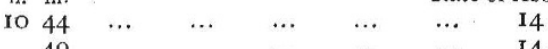

$$
\begin{aligned}
& \begin{array}{lllllll}
49 & \ldots & \ldots & \ldots & \ldots & \ldots & 14
\end{array}
\end{aligned}
$$

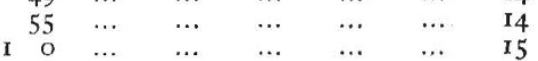

$$
\begin{aligned}
& \begin{array}{lllllll}
5 & \ldots & \ldots & \ldots & \ldots & \ldots & \text { 15 } \\
6 \frac{1}{2} & \cdots & &
\end{array} \\
& \begin{array}{cccccc}
7 \frac{1}{2} ? \ldots & \text { Blind drawn up } & & & \\
& \ldots & \ldots & \ldots & \ldots & \text { 14 }
\end{array} \\
& \begin{array}{ccccccc}
9 & \ldots & \ldots & \ldots & \ldots & \ldots & 20 \\
\mathbf{I} 2 \frac{1}{2} & \ldots & \ldots & \ldots & \ldots & \ldots & 27
\end{array}
\end{aligned}
$$

Thus in six minutes the rate of absorption had nearly doubled. A similarly rapid effect is seen when the sunlight is cut off, when the rate of absorption falls.

$$
\begin{aligned}
& \text { Time h. m. Rate of Abscrption } \\
& \begin{array}{llllllll}
12 & 5 & \cdots & \ldots & \ldots & \cdots & \ldots & 33
\end{array} \\
& \begin{array}{llllll}
\text { I0 } & \ldots & . & \ldots & \ldots & \ldots \\
\text { IO } \frac{1}{2} & \cdots & \ldots & \ldots & \ldots & \text { blind down }
\end{array}
\end{aligned}
$$

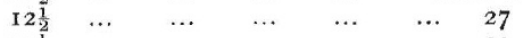

$$
\begin{aligned}
& \begin{array}{lllllll}
\text { I } 9 \frac{1}{2} & \ldots & \ldots & \ldots & \ldots & \ldots & 20
\end{array} \\
& \begin{array}{lllllll}
25 & \cdots & \cdots & \cdots & \cdots & \ldots & \text { 19 } \\
29 & \cdots & \cdots & \cdots & \cdots & \ldots & \text { 18 }
\end{array}
\end{aligned}
$$

That is, the rate of absorption diminished in the proportion of $100: 56$ in twenty-four minutes, when the sunlight was cut off. In the same way the effect of opening a window and thus increasing the evaporation for the leaves, is a once visible in increased rate of movement in the bubble.

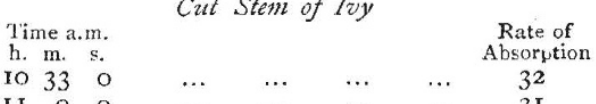

$$
\begin{aligned}
& \text { I I } \begin{array}{rrrrrrr}
0 & 0 & \ldots & \ldots & \ldots & \ldots & 3 \text { I }
\end{array} \\
& \begin{array}{lllll}
9 & 0 & \ldots & \ldots & \cdots
\end{array} \quad \text { window and door opened } \\
& \begin{array}{lllllll}
\text { IO } & 40 & \ldots & \ldots & \ldots & \ldots & 34
\end{array} \\
& \begin{array}{lllllll}
I I & 30 & \ldots & \ldots & \ldots & \ldots & 37
\end{array} \\
& \begin{array}{lllllll}
12 & 0 & \ldots & \ldots & \ldots & \ldots & 37
\end{array} \\
& \begin{array}{rrrrrrr}
18 & 0 & \cdots & \cdots & \cdots & \cdots & 33
\end{array} \\
& \begin{array}{rrrrrrr}
\text { I } 9 & 0 & \ldots & \ldots & \ldots & \text { window and } \\
2 \text { I } & 30 & \ldots & \ldots & \ldots & \ldots & 3 \text { I }
\end{array} \\
& \begin{array}{lllllll}
22 & 30 & \cdots & \cdots & \cdots & \cdots & 31 \\
& 40 & \cdots & \cdots & \cdots & \cdots & 29
\end{array}
\end{aligned}
$$

It need not here be discussed whetker the particular phenomenc n her described is the same as that described by Sachs. 
Effect of Disturbance.-The fact observed by Baranetzky, that a small disturbance, such as a slight shake, increases the transpiration of the leaves, is also easily seen, and my observations show that in some cases the effect may be very transitory. It need not occur in the use of my instrument, since the plant remains quite untouched, the only necessary movement being the removal and replacement of a vessel of water to allow the entrance of a bubble.

Effect of Sudden Diminution of the Evaporating Surface.-I have been astonished to find with what rapidity the rate of absorption diminishes when the evaporating surface is diminished by cutting off a twig from the branch under experiment.

A branch of Portugal laurel was absorbing (April ro) with great regularity.

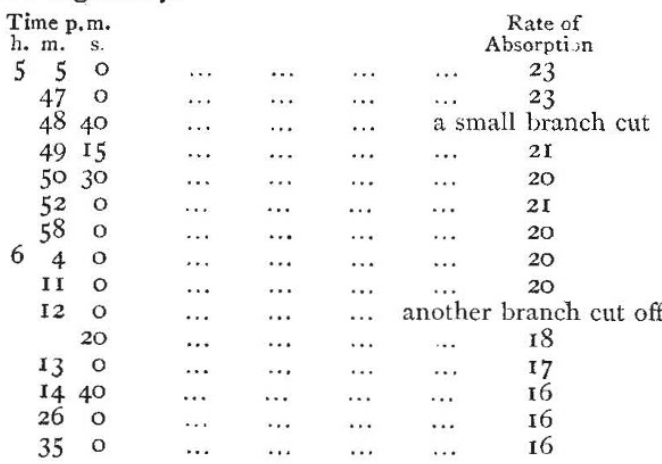

When the first branch was removed nearly the whole of the permanent diminution was visible in $35^{\prime \prime}$; in this case the distance from the base of the branch to the place where the small branch was severed was $28 \mathrm{~cm}$.

In the second experiment half the permanent effect was produced in $20^{\prime \prime}$; and here the distance of the cut-off $t w i g$ from the cut end of the main branch was $45 \mathrm{~cm}$.

But far more remarkable results were obtaine 1 when a long stem of ivy was used for the experiment.

A stem of ivy was removed from the tree on which it grew on April 13, and was placed with its cut end in water until the following day, when it was fitted to the apparatus. ${ }^{1}$

April 14 . - The rate of absorption remained fairly constant from 10.30 to 11.45 a.m., when the first branch was removed.

$$
\begin{aligned}
& \text { Time a.m. } \\
& \text { h. m. s. } \\
& \text { IO } 33 \\
& \text { I I } 420 \\
& 450 \\
& 46 \quad 20 \\
& 530 \\
& \begin{array}{ccccc} 
& & & \multicolumn{2}{c}{\begin{array}{c}
\text { Rate of } \\
\text { Absorption }
\end{array}} \\
\ldots & \ldots & \ldots & \ldots & 32 \\
\ldots & \ldots & \ldots & \ldots & 3 \text { I } \\
\ldots & \ldots & \ldots & \multicolumn{2}{c}{\text { branch cut off }} \\
\ldots & \ldots & \ldots & \ldots & 29 \\
\ldots & \ldots & \ldots & \ldots & 23 \\
\ldots & \ldots & \ldots & \ldots & 26
\end{array}
\end{aligned}
$$

The branch which had teen cut off left the main stem at a distance of 13 feet 3 inches from the basal end, so that change in the rate of absorption was transmitted at the rate of 0.88 feet per second.

In a second trial the following results were obtained :-

$$
\begin{aligned}
& \begin{array}{c}
\text { Time } \\
\text { h. } \mathrm{m} . \mathrm{s} \text {. }
\end{array} \\
& 3 \text { I } \\
& 60 \\
& \begin{array}{r}
6 \\
\text { I } 30
\end{array} \\
& \text { I3 } 0 \\
& \text { I } 5 \\
& \begin{array}{rr}
14 \\
1530
\end{array}
\end{aligned}
$$$$
\text { I5 } 30
$$$$
\begin{aligned}
& \ldots \\
& \ldots \\
& \ldots \\
& \ldots \\
& \ldots \\
& \ldots \\
& \ldots
\end{aligned}
$$$$
\begin{aligned}
& \ldots \\
& \ldots \\
& \ldots \\
& \ldots \\
& \ldots \\
& \ldots \\
& \ldots
\end{aligned}
$$

Rate of
Absorption
23
23
23
stem cut
18
17
15
15

The point at which the stem was severed was 16 feet 5 inches from the basal end, so that here a change in ${ }^{x}$ The stem was fixed so that its distal end was some few feet above the absorption travelled at the rate of $I \cdot I$ foot per second. The same result followed on two other occasions, but here the rates of transmission were slower-

$$
\begin{aligned}
& 15 \text { feet } 5 \text { inches in } 30^{\prime \prime} \text {, } \\
& 9 \text { feet } 10 \text { inches in } 30^{\prime \prime} .
\end{aligned}
$$

In the latter of these two cases the part removed was not a branch of the stem, but a branch belonging to a neighbouring stem which had grown into lateral union with it, so that here the transmission of the change must have taken place laterally from the branch to the stem, and then longitudinally along the latter.

Effect of partly severing the Branch.-My instrument is well adapted for testing the transmitting capacity of a branch which has been partly cut through. I have been much surprised at the fact that cuts to the depth of half or more than half the diameter of the branch produce practically no diminution in the rate of absorption. Indeed a slight increase is often visible owing to the disturbance which must occur when the branch is cut with the saw.

A branch of yew 55 inch in diameter was sawn (A) to the depth of 25 inch, (B) so deep that the bridge of wood through which the water had to pass was not more than $I$ inch in thickness in radial direction.

\begin{tabular}{|c|c|c|c|c|c|c|c|}
\hline \multicolumn{6}{|c|}{$\begin{array}{l}\text { Time a.m. } \\
\text { h. m. }\end{array}$} & \multicolumn{2}{|c|}{$\begin{array}{c}\text { Rate of } \\
\text { Absorption }\end{array}$} \\
\hline & O & $\cdots$ & $\cdots$ & $\cdots$ & $\cdots$ & $\cdots$ & I8 \\
\hline & 9 & $\cdots$ & $\ldots$ & $\cdots$ & $\cdots$ & $\cdots$ & I 8 \\
\hline & 14 & $\cdots$ & $\cdots$ & $\cdots$ & $\cdots$ & $\ldots$ & cut A \\
\hline & I6 & $\ldots$ & $\cdots$ & $\cdots$ & $\cdots$ & $\ldots$ & I6 \\
\hline & 20 & $\ldots$ & $\cdots$ & $\cdots$ & $\cdots$ & $\ldots$ & I 8 \\
\hline & 30 & $\ldots$ & $\cdots$ & $\cdots$ & $\cdots$ & $\cdots$ & I7 \\
\hline I 2 & 0 & $\cdots$ & $\cdots$ & $\ldots$ & $\cdots$ & $\ldots$ & 17 \\
\hline & 6 & $\ldots$ & $\cdots$ & $\cdots$ & $\cdots$ & $\cdots$ & 18 \\
\hline & 8.9 & $\cdots$ & $\ldots$ & $\ldots$ & $\ldots$ & $\cdots$ & cut B \\
\hline & 10 & $\ldots$ & $\cdots$ & $\cdots$ & $\cdots$ & $\cdots$ & 18 \\
\hline & II & $\cdots$ & $\cdots$ & $\cdots$ & $\cdots$ & $\cdots$ & 19 \\
\hline & I 7 & $\cdots$ & $\cdots$ & $\cdots$ & $\cdots$ & $\ldots$ & 17 \\
\hline & 30 & $\ldots$ & $\ldots$ & $\ldots$ & .. & $\ldots$ & 18 \\
\hline & 35 & $\cdots$ & $\cdots$ & $\cdots$ & $\cdots$ & $\ldots$ & cut $\mathrm{C}$ \\
\hline & $36 \frac{1}{2}$ & $\cdots$ & $\cdots$ & $\cdots$ & $\cdots$ & $\cdots$ & 9 \\
\hline & 38 & $\cdots$ & $\ldots$ & $\cdots$ & $\ldots$ & $\ldots$ & 9 \\
\hline & 42 & $\cdots$ & $\cdots$ & $\cdots$ & $\cdots$ & $\cdots$ & IO \\
\hline & 48 & $\ldots$ & $\ldots$ & $\cdots$ & .. & $\ldots$ & 12 \\
\hline & $\begin{array}{l}55 \\
\mathrm{~m} .\end{array}$ & $\cdots$ & .. & $\cdots$ & $\cdots$ & $\ldots$ & 14 \\
\hline I & I 5 & $\cdots$ & $\cdots$ & $\ldots$ & $\cdots$ & $\ldots$ & 16 \\
\hline
\end{tabular}

\begin{tabular}{ccccccc}
$\begin{array}{c}\text { Time p.m. } \\
\text { h. } \mathrm{m} .\end{array}$ & & & & \multicolumn{3}{c}{$\begin{array}{c}\text { Rate of } \\
\text { Abscrption }\end{array}$} \\
326 & $\ldots$ & $\ldots$ & $\ldots$ & $\ldots$ & $\ldots$ & 99 \\
32 & $\ldots$ & $\ldots$ & $\ldots$ & $\ldots$ & $\ldots$ & 99 \\
34 & $\ldots$ & $\ldots$ & $\ldots$ & $\ldots$ & $\ldots$ & cut A made \\
35 & $\ldots$ & $\ldots$ & $\ldots$ & $\ldots$ & $\ldots$ & 98 \\
40 & $\ldots$ & $\ldots$ & $\ldots$ & $\ldots$ & $\ldots$ & 103 \\
47 & $\ldots$ & $\ldots$ & $\ldots$ & $\ldots$ & $\ldots$ & IOI \\
4 & $\ldots$ & $\ldots$ & $\ldots$ & $\ldots$ & $\ldots$ & 99 \\
37 & $\ldots$ & $\ldots$ & $\ldots$ & $\ldots$ & $\ldots$ & 99 \\
$38 \frac{1}{2}$ & $\ldots$ & $\ldots$ & $\ldots$ & $\ldots$ & $\ldots$ & cut B made \\
40 & $\ldots$ & $\ldots$ & $\ldots$ & $\ldots$ & $\ldots$ & IOO \\
43 & $\ldots$ & $\ldots$ & $\ldots$ & $\ldots$ & $\ldots$ & 97 \\
46 & $\ldots$ & $\ldots$ & $\ldots$ & $\ldots$ & $\ldots$ & 100 \\
50 & $\ldots$ & $\ldots$ & $\ldots$ & $\ldots$ & $\ldots$ & I00
\end{tabular}

It was only when the bridge remaining after cut $B$ was narrowed, by sawing on both sides at right angles to the former direction, that the rate of absorption fell. The same thing was shown in another branch of yew, the woody part of which was $10 \mathrm{~mm}$. in diameter, and which was sawn to a depth of $8 \mathrm{~mm}$., leaving a bridge $2 \mathrm{~mm}$. thick in radial direction. Even this deep section did not diminish the rate of absorption. With the Portugal laurel the same thing was observed; and here the possibility of recovery from a temporary diminution in absorption was shown in two cases.

The branch with its bark on measured $11 \mathrm{~mm}$, in diameter, and it was traversed by an excentric cylinder of old brown wood $1.8 \mathrm{~mm}$. in dianseter.

The following figures give the result of section :- 
It will be seen that the two first cuts produced no effect comparable to that caused by C. Cut A was $3 \mathrm{~mm}$. deep, cut $B$ was also $3 \mathrm{~mm}$. deep on the opposite side, so that, after $\mathrm{B}$ had been made a bridge, $5 \mathrm{~mm}$. in radial direction remained ; nevertheless the rate of absorption was undiminished. Cut $\mathrm{C}$ was made by increasing $\mathrm{B}$ to the depth of $5 \mathrm{~mm}$. from the bark, so that the bridge of more or less central wood finally left was $3 \mathrm{~mm}$. in radial thickness, and even then the diminution was only temporary. The cuts were made about $7 \mathrm{~cm}$. from the basal end, and the same distance from the first branch. Another branch of Portugal laurel showed the same thing. The wood of the branch at the point of section was about a centimetre in diameter, and contained a large proportion of old brown wood. The external envelope of white wood was cut away with the exception ${ }^{1}$ of a bridge measuring roughly $3 \times 3.5 \mathrm{~mm}$. in cross section.

The result is shown in the following table :-

Time p.m.
h. m.
I 34
2 I3
I6 6
I $9 \frac{1}{2}$
21
21
26
32
32
39
47
53

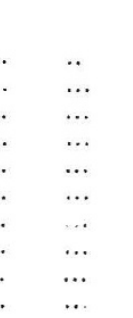

$\begin{array}{ll} & \\ \ldots & \\ \ldots & \\ \ldots & \\ \cdots & \cdots \\ \ldots & \cdots \\ \ldots & \cdots \\ \cdots & . \\ \ldots & . \\ \ldots & . \\ \cdots & .\end{array}$

\begin{tabular}{|c|}
\hline $\begin{array}{l}\text { Rate of } \\
\text { Absorption }\end{array}$ \\
\hline 15 \\
\hline 15 \\
\hline cut \\
\hline 10 \\
\hline II \\
\hline I3 \\
\hline 14 \\
\hline 13 \\
\hline 14 \\
\hline I 5 \\
\hline
\end{tabular}

Here again we have a diminution followed by gradual rise.

When the little bridge of younger wood was severed, the fall in rate of absorption was rapid.

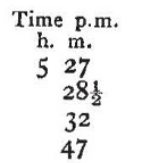

$$
\begin{aligned}
& \begin{array}{c}
\text { Rate of } \\
\text { Absorption }
\end{array} \\
& \text { I6 } \\
& \text { bridge severed } \\
& 0.12 \\
& 0.08
\end{aligned}
$$

Thus the absorption fell to one-twentieth of the original amount; that it did not quite cease may be accounted for by the fact that the younger circumferential wood was not completely cut through.

My apparatus would be also suitable for such experiments as those of Dufour (Arbeiten d. Bot. Inst. in Würzburg, 1884, Band iii.), in which he showed that sharply bending a stem, such as a hop-bind, does not prevent the passage of the water of transpiration, whereas water could not be mechanically forced through the bent stem. Dufour also repeated Hales' experiments in which the transpiring branch was cut half through on two opposite sides, the points of section being an inch or two apart. When this had been done, so that the continuity of all cavities of vessels and cells was broken, he found that the transpiration-stream could still pass, because the continuity of the cell-zwalls remained unbroken. I give a single experiment of this kind to show that my instrument is well adapted for such work (April I 5) :-

$$
\begin{array}{cccccc}
\multicolumn{2}{c}{\text { Time }} \\
\text { h. m. }
\end{array}
$$

Both cuts penetrated to the centre of the branch. The first was one and a half inch from the base, the second

The young wood was not well severed, and a small amount remained in half an inch below the first cut, and on the opposite side of the branch.

Dufour's experiments would seem to show that the great depression in absorption which occurred on making the ؛ econd cut may have been only a temporary phenomenon; this and other $\mathrm{k}$ ndred questions I hope soon to be able to work out.

Cambridge, April 17

FRANCIS DARWIN

\section{WHAT IS A LIBERAL EDUCATION? I}

I DO not intend, in the present paper, to enter upon the disputed question between the advocates of classical culture on the one hand, and those of scientific training on the other; because it seems to me that the line on which the two parties divide is not that which really divides the thought of the day. If we look closely into the case, we shall see that the objects of a higher education may be divided into three classes, instead of the two familiar ones of liberal and professional. In fact, what we commonly call a liberal education should, I think, have two separate objects. With the idea of a professional education we are all familiar: it is that which enables the possessor to pursue with advantage some wealth-producing specialty. Although, in accordance with well-known economic principles, it is designed to make the individual useful to his fellow-men, the ultimate object in view is the gaining of a livelihood by the individual himself. On the other hand, the object had in view in what is commonly known as culture is not the mere gaining of a livelihood, but the acquisition of those ideas, and the training of those powers, which conduce to the happiness of the individual. From this point of view culture may be considered an end unto itself.

The third object which we have to consider is only beginning to receive recognition in the eyes of the public. It is the general usefulness of the individual, not merely to himself and to those with whom he stands in business relations, but to society at large. Modern thought and investigation lead to the conclusion, that man himself, the institutions under which he lives, and the conditions which surround him, are subject to slow, progressive changes; and that it depends very largely on the policy of each generation of mankind whether these changes shall be in the way of improvement or retrogression. During the next fifty years all of us will have passed from the stage of active life, and the course of events will be very largely directed by men who are still unborn. The happiness of those men is, from the widest philanthropic point of viewr, just as important as the happiness of those who now inhabit the earth; and, in the light of modern science, we now see that that happiness depends very largely upon our own actions. We thus have opened out to us an interest and a field of solicitude in which we need the best thought of the time. The question is, What form of education and training will best fit the now rising generation for the duty of improving the condition of the generation to follow it?

Let it be understood that we are now speaking, not of the education of the masses, but of that higher education which is necessarily confined to a small minority. So far as I am aware, that fraction of the male population which receives a college education is not far from I per cent. To that comparatively small body we must look for the power which is to direct the society of the future, and by their acts to promote the well- or ill-being of the coming generation. Our duty to that generation is to so use and train this select body as to be of most benefit to the men of the future. What is the training required? I reply by saying that I know nothing better for this end than a wide and liberal training in the scientific spirit and the scientific method. The technicalities of science are not the first object ; and, so far as they are introduced, it is only 